\title{
Mental Reengineering as an Intellectual Technology of Human Resources Quality Management in a Modern Organization
}

\author{
Irina Lyskova \\ The Economics and Management Department \\ The Komi Republican Academy of State Service and Administration \\ Syktyvkar, Russia \\ E-mail: IrinaLyskova@mail.ru
}

\begin{abstract}
The paper studies the main tasks of quality management and the importance of rational approaches to the human resources management in an organization. The paper provides the general characteristics of business processes and human resources reengineering. Moreover, it emphasizes the importance of intellectual technologies in the aspect of quality management, reveals the essence of mental reengineering as the intellectual technology of the modern human resources quality model and the strategic development of an organization.
\end{abstract}

Keywords-organization; quality management; human resources management; human resources quality; intellectual technologies of quality management; reengineering; mental reengineering; labor motivation

\section{INTRODUCTION}

The key tasks of the socioeconomic evolution of Russia envisage an urgent need to accelerate the rates of economic growth and innovative development, to improve the level of social welfare and the quality of life of the population. The rapid development of information technologies, the acknowledging the value of innovation and improving the technological level of production, increasing labor productivity, qualitative renewal of business processes, active introduction of resource-saving technologies, improving labor protection and safety system, as well as new quality of human resources altogether determine the basic characteristics of the modern knowledge economy.

The concept of knowledge management, as a system for managing intellectual assets of an organization, took shape in the early $90 \mathrm{~s}$ of the 20th century. The intellectual technologies development aimed at ensuring the quality of production processes implies a set of cognitive, socioeconomic, emotional and psychological resources of an organization. In the modern socio-economic situation, the concept of knowledge management is based on the transformation of individual knowledge and competencies of employees into a system of effective intellectual technologies, intellectual potential and intellectual capital of an organization, which form the basis of the strategy and tactics of an organization's development [1] [2] [3] [4]. The main tasks of the research include the mainstreaming of the role of human resources as a powerful factor in modern organizations effectiveness, analyzing the human resources quality model in an organization, revealing the essence of mental reengineering as an intellectual technology forming the quality of human resources in an organization.

\section{CONCEPTIONS OF THE QUALITY MANAGEMENT}

It is necessary to note that the political and socioeconomic situation of the last quarter of the 20th century predetermined the importance of new approaches to the formation of integrated quality management systems for products, goods, services, business processes, and management systems. Gradually a new concept of quality management (Total Quality Management) was formed. The key principles of the new quality management system appeared to be the following: the principles of strategic customer orientation; the increasing role of management in the process of forming an effective quality management system; increasing employees engagement in the quality management process; ensuring process and system approaches to management; constant improvement, making effective decisions and setting mutually beneficial relations with suppliers (ISO 9000, ISO 9001, QS-9000).

Improvement of the business processes within an organization is connected with improving the activities, forming the systems and processes management, organization's quality policy, an effective resource management system, increasing management responsibility, social responsibility of an organization, etc. (ISO 9004: 2000, ICCSR 26000: 2011). Project activity (ISO 10006, ISO 21500) gained a wide spread in the practice of innovations aimed at organizational development. What is more, the modern knowledge economy sets high requirements to the employees.

The concepts of quality management have received worldwide recognition. The concept of managing the quality of human resources is also acquiring exceptional significance. The role of the human factor in the production system is becoming more and more obvious. The technocratic approach in personnel management that used to prevail 
earlier began to lose its positions. In the 1980s, Western management system started to pay special attention to the tasks of continuous development of organizations' nonmaterial assets, that is, human resources themselves. It is then that the concept of human capital entered in the scientific circulation; the essence of the organization's policy stimulating employees' retention within an organization was revealed; the necessity of human resources effective planning was realized; the tasks of performance management were justified, etc. In the 1990s, Western management practices began to focus on the model of strategic human resource management. This model was primarily aimed at strategic planning of human capital, whereas the latter was defined as a set of experience, skills and knowledge that employees of an organization have [5] [6].

However, the Japanese view on the tasks of shaping the quality of the human resources of an organization was no less interesting. Awareness of the importance of quality problems in Japan took place even earlier than in the West. K. Ishikawa is known to be one of the founders of the Japanese model of quality. Quality management became part of the public policy system. The idea of universal quality control was introduced in the mass consciousness of Japanese people, and by the end of the 1960s, the Japanese model of the quality management system was completely formed. Its specifics included the following characteristics: 1. Total quality management in an organization and involvement of all employees in this process; 2. Staff training and professional development in the field of quality management; 3. Effective functioning of quality circles; 4. Inspection and evaluation of quality management activities; 5. Use of statistical methods; 6. Implementation of a national quality control program.

The special features of the Japanese quality management system have already been attracting the attention of specialists in the field of management theory and practice for several decades. It is important to note that the staff of Japanese organizations has a very high level of professional qualification, possesses a wide range of competences, and is characterized by inexhaustible motivation for work as well as an exceptional degree of responsibility and labor discipline.

In modern conditions, the Japanese philosophy and practice of kaizen are of great interest, as the goal of kaizen is to improve modern business processes. Kaizen, as a system and process of continuous improvement, is characterized, first of all, by the employees' specific style of thinking. According to the concept of kaizen, all efforts of the organization should be aimed at satisfying the needs and serving consumers. Moreover, kaizen forms a unique way of thinking, focused on improving technological, organizational, managerial processes (process thinking). The main philosophical idea of kaizen reflects the very model of attitude to life, the formation of a special image and quality of life, in the field of professional and social activities, family and personal life, which altogether deserve constant improvement.

The Japanese quality management model is characterized by: a continuous increase in labor productivity, the introduction of a total quality control system, the effective work of quality circles, continuous improvement of the system of labor relations, robotization, automation, high labor discipline, total maintenance of production equipment, the efficiency of small group activity, the timeliness of supply, cooperation development, new products development and implementation in a short time, etc. The universally recognized rational tools of continuous improvement are the following: high discipline, effective time management, developing professional and personal skills, cooperation and full involvement in the process, high morale and effective communication [7] [8].

\section{REENGINEERING OF BUSINESS PROCESSES AND HUMAN RESOURCES REENGINEERING}

Among the characteristic features of the subjective personality traits that determine the quality of both human resources and the process of intellectual technologies improvement, one can recognize creativity based on nonstandard approaches to the accomplishing professional tasks and making managerial decisions; intuition based on personal experience, extraordinary intellectual abilities of an employee; bricolage, which provides the ability to show as high performance as possible in the conditions of limited resources; flexible adaptation of an employee to the constantly changing conditions of the internal and external environment; compression, as an ability to improve the structure and content of work in a time-saving environment; innovations that require new approaches to solving professional tasks in conditions of uncertainty, increased risk, deviation from existing practices and traditions; continuous professional development based on high internal motivation and commitment to the interests of an organization. The modern economy is experiencing the need of new ideas and unique approaches to solving non-standard problems that can be realized by people with new thinking technologies, a high intellectual level, endowed with creative, innovative potential, aimed at achieving high performance in labor process and result. In terms of providing qualitatively new approaches to the human resources management, the theory and practice of human resources reengineering are of considerable interest [9] [10].

Reengineering as a new course of management emerged in the 1990s. M. Hammer and J. Champi are considered to be the authors of the concept of reengineering (reconstruction of business processes). Reengineering of business processes is correlated with the achievement of qualitatively new, spasmodic improvements in key performance indicators of the organization (quality, service and speed). The reconstruction of business processes itself involves a standardized cycle, which includes the following steps:

- Coordinating the reconstruction process with organizational strategy.

- Analysis of the essence of existing business processes, aimed at identifying their purpose, understanding the possibility of their improvement and efficiency. 
- Defining a set of improved processes that provide added value, inter alia as a result of combining them with other processes.

- Implementation of improving processes and ensuring their monitoring.

- Launching a new cycle of improving business processes.

In practice, reengineering is effective for organizations in crises; therefore, the process of reconstruction is seen as inevitable. Rationality of reengineering is also justified for the organizations occupying leading positions, inclined to growth and provision of competitive advantages. It is vital to note the importance of social aspects of the process of reengineering, in particular, the reengineering of human resources, including new approaches to the process of motivating labor activity. In the process of human resources reengineering, it is especially important to distinguish competence, cognitive, existential and axiological approaches [11] [12]. These approaches prove the need to live, work, and think in a new way. Behind mental reengineering, as an original intellectual technology, is the deep awareness of all the processes of an individual's vital activity, the understanding of the exceptional importance of personal and professional goals and values, the comprehension of life experience, the quality of selfrealization of an individual in the sphere of professional activity [13] [14] [15].

\section{MENTAL REENGINEERING}

The conception of mental reengineering can be built on the basis of the multidimensional structure of a personality's intellect. The search for modern technologies for motivating labor activity can be guided by at least four key components: physical intelligence, which reflects the essence of the psychophysiological foundations of professional activity (quality of working life, work and rest regime, sanitary and hygienic standards of work, working conditions, employee health, physical and mental state of health, level of stressresistance, etc.); intellectual intelligence that characterizes the cognitive abilities of an individual, the level of education and professional qualifications, the level of cognitive culture of an individual, in general, intellectual abilities (logical, analytical, critical, creative, strategic, systemic thinking, etc., which form the basis of a rational way of cognizing the world); spiritual intellect, which forms the basis of the spiritual and moral culture and the system of values of an individual, actualizing the tasks of managing needs and the importance of personality education; emotional intelligence, which combines the totality of personal and social skills of a person, fully uncovered in the field of professional activity.

Practically here is no doubt about the need to improve not only the mental, but also the emotional potential of a person. Emotional intelligence is a complex characteristic that combines the totality of psycho-physiological, social, cultural and spiritual-moral foundations of a person's life. Purposeful development of emotional intelligence is designed to provide various opportunities for self-realization of employees in the field of professional activity, and not only. Modern intellectual technologies provide for new approaches to the management of human resources. Emotional leadership based on emotional intelligence is gaining exceptional significance in the designated context. Favorable working atmosphere, positive, optimistic attitude, enthusiasm, inspiration, trust, openness, engagement, etc. contribute to unlocking the intellectual, creative potential of an individual, provide a high degree of satisfaction and a desire to work, continuously develop and improve. The socio-psychological climate is formed under a leader himself Accordingly, one of the relevant tasks of a modern leader is the development of their own emotional intelligence, that is, the skills and habits of managing themselves as well as the relations in a team [16] [17] [18] [19] [20] [21] [22] [23].

Among the key components of emotional intelligence, providing the basic directions of mental reengineering there are two groups of skills - personal and social. Personal skills include the ability of a person for self-consciousness. It reflects the ability to realize one's own emotions, the presence of intuitive abilities, unconsciously supporting the decision-making process; At the same time, selfconsciousness provides an opportunity for accurate, adequate self-esteem, the ability to identify personal strengths and weaknesses and capabilities. Self-confidence is recognized as a weighty characteristic as well, based on self-esteem and recognition of the dignity of others. Along with selfconsciousness, personal skills include self-control, which implies the ability to control emotions; openness in relationships; a high degree of adaptability to the inevitable changes; significant emotional and strong-willed potential with a focus on high standards of quality and achievement; initiative; optimism.

If personal skills are more a record of our ability to control ourselves, social skills reflect the ability to manage relationships with people. These skills consist of two components, the first of which is social sensitivity. It includes such characteristics as empathy for other people's feelings, understanding and participation in a current situation. In addition, business awareness of current events in an organization and the warning, that is, the orientation to the needs of subordinates or customers, is of high importance, too. The second component of social skills that form emotional intelligence is relationship management. Its distinguished qualities are the following: inspiration; influence; assistance in the process of self-improvement; promoting qualitative changes; ability to resolve conflicts; strengthening personal relationships, development of social ties; organizing teamwork and cooperation.

\section{CONCLUSION}

Thus, in modern socio-economic conditions, the need to search for new efficient technologies for the development of human resources capable of ensuring the quality of business processes, qualitative self-renewal, continuous professional development, and personal self-improvement becomes more and more obvious. The development strategy of an organization should include a set of goals and activities to 
create the necessary conditions for improving the quality of human resources.

\section{REFERENCES}

[1] I.E. Lyskova, The problems of human capital management in the aspect of modern knowledge economy Journal of economy and entrepreneurship. 2017. No. 9 (P. 4) (84-4), pp. 641-645.

[2] I.E. Lyskova, Moral concepts of modern business processes // International Conference on Judicial, Administrative and Humanitarian Problems of State Structures and Economical Subjects (JAHP 2016) // Atlantis Press, Amsterdam-Hong Kong-Paris, 2016, pp. 37-41 // www.atlantis-press.com/php/pub.php?publication=jahp16.

[3] I.E. Lyskova, Socio-Cultural Aspect of Thriftiness. 2nd International Conference on Economy, Management, Law and Education (EMLE 2016) // Advances in Economics. Business and Management Research. Vol. 20. Atlantis Press, Amsterdam-Hong Kong-Paris, 2016, pp. 152-154 // www.atlantispress.com/php/pub.php?publication=emle-16

[4] I.E. Lyskova, Main Paradigms of Creative Management in the Aspect of Modern Cognitive Economy // International Conference on Culture, Education and Financial Development of Modern Society (ICCESE 2017) Vol. 103. Atlantis Press, Amsterdam-Hong Kong-Paris. 2017. Pp. 644-649 // www.atlantispress.com/php/pub.php?publication=icctse-2017

[5] S. Adizes, Mastering Change. The Power of Mutual Trust and Respect in Personal Life, Family Life, Business and Society. Moscow. Mann, Ivanov and Ferber. 2016, - $368 \mathrm{p}$

[6] M. van Assen, G. van den Berg, P. Pietersma, Key Management Models. The 60+ Models Every Manager Needs to Know. Moscow, BINOM, Laboratoriya Znaniy. 2013. - 319 p., pp. 95-98

[7] M. Imai, Kaizen, The Key to Japan's Competitive Success. Moscow: Alpina Publisher, 2015, $274 \mathrm{p}$.

[8] K. Ohmae, The Mind of the Strategist. The Art of Japanese Business. Moscow. 2015, $211 \mathrm{p}$.

[9] E. Lyskova, The Main Paradigms of Human Resources Quality Management in the Aspect of Modern Cognitive Economy. The Herald of the Management Faculty of the Saint-Petersburg State University of Economics. 2017, vol. 1. P.1, pp 60-65.

[10] E. Lyskova, Intellectual Technologies as the Basis of the Innovative Model of Management of Quality of Human Resources of the organization. National Concepts of Quality: the Integration of Education, Science and Business. The Collection of Articles of the VIII International Research and Practice Conference. St. Petersburg, 2017, pp. 99-102.

[11] A.O. Blinov, I.E. Lyskova, Self-management in modern reengineering of human resources. Journal of economy and entrepreneurship. 2016. No. 3-1 (68-1), pp. 622-626.

[12] I. Lyskova, Self-Management in the Aspect of Modern Reengineering of Human Resources. The scientific heritage. (Budapest, Hungary). 2016, vol. 1. No 3 (3), pp. 7-9.

[13] S.R. Covey, The 7 Habits of Highly Effective People. Restoring the Character Ethics. Moscow: Alpina Publisher. 2015. - 396 p.

[14] I. Lyskova, Basic Principles of Self-Management as a Technology of Modern Reengineering of Human Resourses in an Organization. Application of new technologies in management and economy. 5th International Conference. 21-23 April 2016, Belgrade, Serbia). Belgrade, 2016, vol. 2. pp. 99-106.

[15] I.E. Lyskova, Cognitive and Creative Management as a Basis of Innovative Development of Modern Organization. Public and Private Finances in the Innovative Economy. The Collection of Articles of the International Research and Practice Internet Conference. Plekhanov Russian University of Economics, Moscow. 2017, pp. 123-132.
[16] A.O. Blinov, I.E. Lyskova, Conceptual basis of forming of ethical culture business-processes in modern organization. Journal of economy and entrepreneurship. 2016. No. 2-1 (67-1), pp. 931-937.

[17] D. Goleman, Emotional Intelligence. Why It Can Matter More Than IQ. Moscow. Mann, Ivanov and Ferber. 2017, 544 p.

[18] D. Goleman, R. Boyatzis, A. McKee, Primal Leadership. Learning to Leed with Emotional Intelligence. Moscow, Alpina Publisher, 2017, $301 \mathrm{p}$.

[19] [19] R. Judkins, The Art of Creative Thinking. 2016. Moscow: Azbuka Biznes, Azbuka-Attikus, $432 \mathrm{p}$.

[20] J. O'Connor, I. McDermott, The Art of systems thinking. Essential skills for creativity and problem solving. Moscow: Alpina Publisher. $2015,256 \mathrm{p}$

[21] M. Csikszentmihalyi, Flow. The psychology of optimal experience. Moscow: Smysl, Alpina Non-Fiction, 2015, 461 p.

[22] M. Csikszentmihalyi, The Evolving Self. A Psychology for the Third Millennium. Moscow: Alpina Non-Fiction, 2013, 420 p.

[23] D. Sherwood, Seeing the forest for the trees. A Manager's Guide to Applying Systems Thinking. Moscow: Alpina Publisher. 2016, 300 p. 